Portland State University

PDXScholar

1983

\title{
The utility of alternate theoretical conceptualizations of "urban environment" in explaining variation in attitudes and behaviors
}

John Conrad Allen III

Portland State University

Follow this and additional works at: https://pdxscholar.library.pdx.edu/open_access_etds

Part of the Place and Environment Commons, and the Urban Studies and Planning Commons Let us know how access to this document benefits you.

\section{Recommended Citation}

Allen, John Conrad III, "The utility of alternate theoretical conceptualizations of "urban environment" in explaining variation in attitudes and behaviors" (1983). Dissertations and Theses. Paper 322.

https://doi.org/10.15760/etd.3221

This Thesis is brought to you for free and open access. It has been accepted for inclusion in Dissertations and Theses by an authorized administrator of PDXScholar. Please contact us if we can make this document more accessible: pdxscholar@pdx.edu. 
AN ABSTRACT OF THE THESIS OF John Conrad Allen III for the Master of Science in Sociology presented May 20, 1983.

Title: The Utility of Alternate Theoretical

Conceptualizations of "Urban Environment"

in Explaining Variation in Attitudes and

Behaviors.

APPROVED BY MEMBERS OF THE THESIS COMMITTEE:

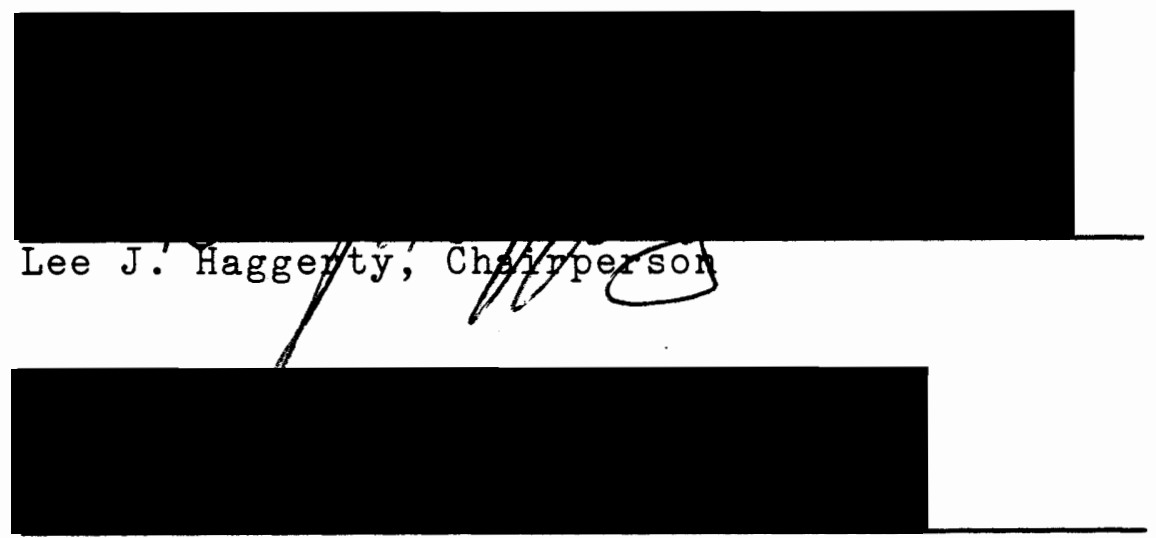

Leonard Cain

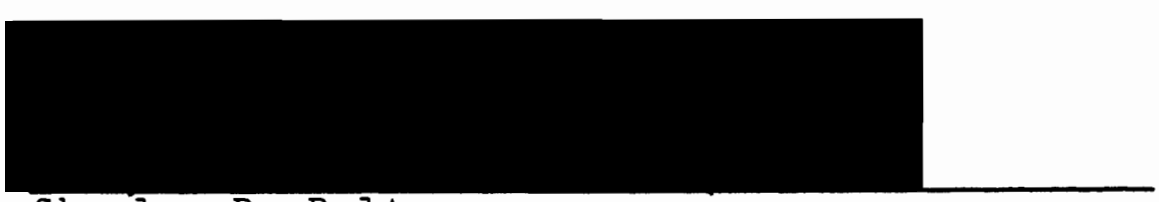

Charles D. Bolton

The debate over what factors actually influence behaviors and attitudes of urban residents is the impetus which generated the idea behind this study. Urban literature suggests several explanations for attitudes including for example, alienation and anomia. These same explanations are assumed to influence behaviors such as: 1) smaller number of children, 2) involvement in voluntary organiza- 
tions, 3) specialized voting behavior and 4) less kinship contact.

The four theoretical perspectives that were analyzed in this study are: 1) demographic concentration, 2) the structure of everyday activities, 3) social class and, 4) the exposure to the symbolism of urban life via television. The utility of each of the four perspectives was examined using cross tabulation and analysis of variance to include all the perspectives in a complete model.

When each perspective was analyzed using just crosstabulation, as is often done to test each perspective, the results were similar to those suggested in the literature. That is, population concentration does seem to influence alienation and anomia, as well as behaviors such as: fewer children, voluntary association membership, and voting behavior. The structure of everyday activities, when using zero order correlates, also is found to influence the above mentioned attitudes and behaviors, along with the exposure to the symbolism of urban life via television.

But, when analysis of variance is utilized, allowing for the control of each theoretical perspective, these findings are found to be spurious. The significant finding of this exploratory study is that when these four perspectives are analyzed in a complete model it is the exposure to the symbolism of urban life via television that is involved in influencing through a main effect or an interactive effect seven of the ten attitudes and behaviors analyzed. 
The findings suggest that urban sociologists must incorporate into their analysis the advance of technology and the symbolism communicated via television, if they are to fully understand the influence of cosmopolitan life on the attitudes and behaviors of urban individuals. 


\title{
THE UTILITY OF ALTERNATE THEORETICAL CONCEPTUALIZATIONS OF "URBAN
}

\author{
ENVIRONMENT" IN EXPLAINING \\ VARIATION IN ATTITUDES \\ AND BEHAVIORS
}

by

JOHN CONRAD ALLEN III

A thesis submitted in partial fulfillment of the requirements for the degree of

MASTERS OF SCIENCE

in

SOCIOLOGY

Portland State University

1983 
TO THE OFFICE OF GRADUATE STUDIES AND RESEARCH:

The members of the Committee approve the thesis of John Conrad Allen III presented May 20, 1983.

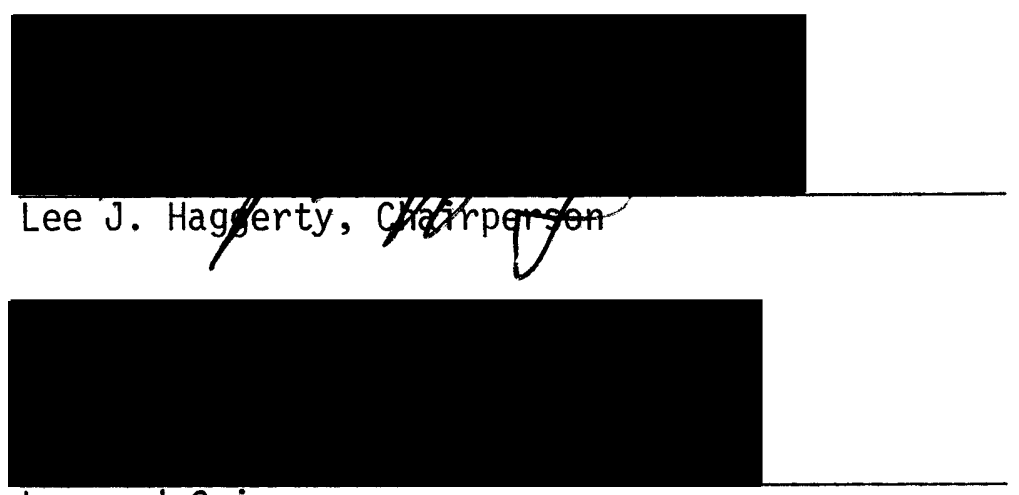

Leonard Cain

Charles D. Bolton

APPROVED:

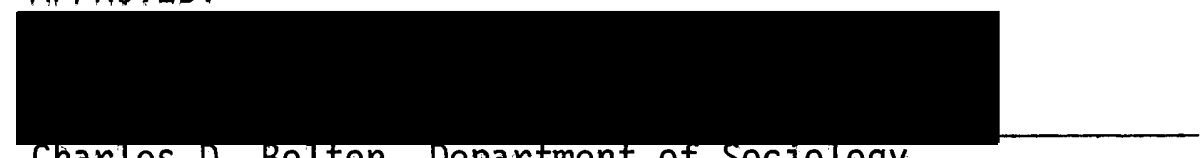

Charles D. Bolton, Department of Sociology

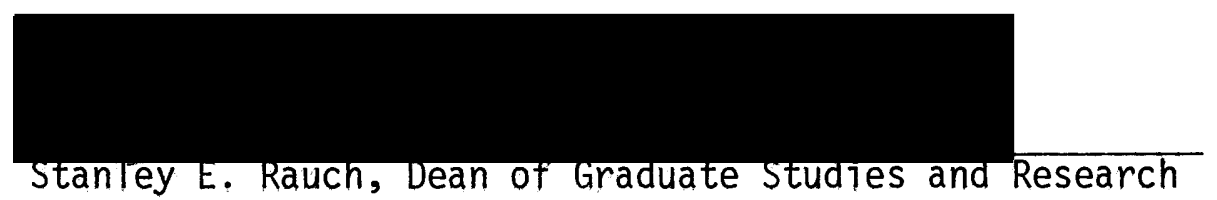


I am indebted to many people for their critical reviews of earlier drafts of this thesis. Without the critical comments that I received this thesis would have been very rough. In particular, I wish to acknowledge my debt to Dr. John Longres, who guided me through the literture concerning Karl Marx; Dr. Grant Farr, who provided methodological support, Dr. Charles Bolton, who provided a critical eye of my writing style, and Dr. Leonard Cain, who provided much needed help in reorganizing the findings presented in this study.

I am especially indebted to Dr. Lee J. Haggerty, who showed me the possibilities that exist for the field of sociology and spent many laborious hours reading and rereading the many drafts that I have submitted for review. Without the support and guidance of Dr. Haggerty this study would have never gotten off the ground. The strengths of this study are attributed to those individuals who guided me through the study and the presentation of the findings. The flaws that exist are mine alone.

A final and special word of thanks must go to Mr. and Mrs. John C. Allen Jr., who provided economic as well as moral support through the rough times; Jean Ellis, who provided much needed support throughout the study; and my wife Kathy, who has been the foundation making it possible. 
PAGE

ACKNOWLEDGMENTS ........................ ii

LIST OF TABLES $\ldots \ldots \ldots \ldots \ldots \ldots \ldots \ldots \ldots \ldots \ldots \ldots \ldots \ldots \ldots$

CHAPTER

I INTRODUCTION .................

II REVIEW OF LITERATURE............ 5

DEMOGRAPHIC CONCENTRATION........ 6

THE STRUCTURE OF EVERYDAY

ACTIVITIES ................ 9

EXPOSURE TO THE SYMBOLISM OF URBAN LIFE VIA TELEVISION............. 11

SOCIAL CLASS............... 14

SUMMARY................. 15

III METHODOLOGY............... 17

LIMITATIONS OF DATA SET......... 18

STATISTICAL METHODS........... 18

OPERATIONALIZATION OF THEORETICAL CONSTRUCTS................ 20

IV $\quad$ FINDINGS................... 26

THE UTILITY OF EXPOSURE TO THE SYMBOLISM OF URBAN LIFE......... 30

THE UTILITY OF THE STRUCTURE OF EVERYDAY ACTIVITIES........... 40

THE UTILITY OF SOCIAL CLASS...... 42

THE UTILITY OF DEMOGRAPHIC

CONCENTRATION................ 44

SUMMARY.................. 44

V CONCLUSIONS................. 46 
PAGE

BIBLIOGRAPHY ......................... 50

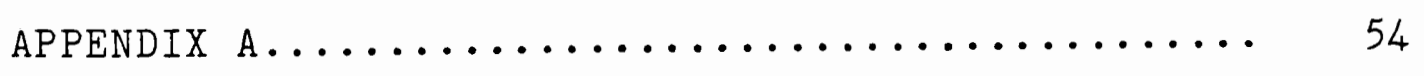

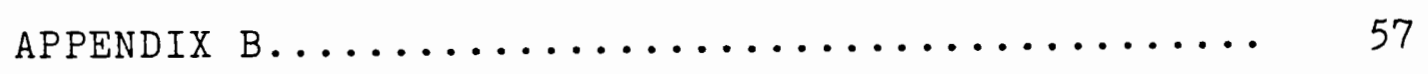




\section{LIST OF TABLES}

TABLE

PAGE

I Percentage Distribution on Selected

Attitudes by Theoretical Perspectives...

II Percentage Distribution on Selected

Behaviors by Theoretical Perspectives...

29

II Significance Level of $F$ for Comparison

of Four Theoretical Perspectives in

Explaining Variation in Selected

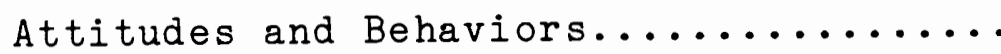




\section{CHAPTER I}

\section{INTRODUCTION}

Urban sociologists have, for some time, debated over what factors actually influence attitudes and behaviors of urbanites. In this thesis, four distinct factors, and the theoretical arguments which have developed around each of the four, have been selected for examination, with the objective of determining which factor has the greatest influence on attitudes and behavior. This study does not analyze the causal direction of the influence nor is the objective to verify any of the four theoretical positions but to test whether or not one of the theories, when analyzed in a complete model, can explain more variation in the responses than the others. The four factors are: 1) demographic concentration, 2) the structure of everyday activities, 3) social class, and 4) exposure to the symbolism of urban life via television.

The first theory to be analyzed is the hypothesis focussing on demographic concentration. Theory, as refered to in this study, is based on the definition of Kerlinger, "A theory is a systematic account of the relations among a set of variables" (Kerlinger, 1979). This theoretical position was based on Louis Wirth's (1938) argument that individuals who live in an urban environment, i.e., large populated areas, densely situated and with heterogeneous population mixes, have different attitudes and behaviors 
than those individuals who live in a rural area. Wirth suggested that urbanites have less kinship contact with their families, which leads to involvement in voluntary organizations to make up for this loss of primary interaction. Wirth also suggested that urbanites are more likely than rural individuals to be involved in specialized voting patterns because of the many social worlds that they take part in. To test the actual influence of demographic concentration on these specific attitudes and behaviors Wirth's position will be included in this analysis.

The structure of everyday activities has been selected based on the argument presented by Emile Durkheim, which indicates that it is not population size but the structure within which individuals interact that influences their attitudes and behavior. Durkheim suggests that as the diversity within a society increases individuls are more likely to become alienated and anomic. This position is based on Durkheim's analysis of the division of labor. Durkheim believed that, as occupational diversification occurred, individuals interacted on a secondary level rather than a primary level leading them to feel alienated and anomic. Based on Durkheim's assumption that occupational diversification influences alienation and anomie the structure of everyday activities has been included in this analysis.

Karl Marx in his theory of social class felt that attitudes and behaviors are influenced by individuals' 
placement in the social system. Eric Wright and Luca Perone (1977) have developed an empirical operation of social class in an attempt to empirically analyze the influence of social placement on behaviors and attitudes. In this particular analysis the Wright/Perone operationalization could not be used, so a scale based on employment status was developed to analyze the influence of social class on alienation and anomia.

With the advent of mass media, particularly television, several authors have suggested that attitudes and behaviors are influenced by this medium. Marshall McLuhan (1964) indicates that over-stimulation produced by television influences attitudes of alienation and powerlessness. He also suggests that individuals are not influenced by population size but by their continual interaction with television. To test McLuhan's theory of the influence of television on attitudes such as alienation and anomia and on behaviors such as: number children, voting or not voting in presidential elections, and membership in voluntary organizations, the number of hours an individual watches television has been selected to test McLuhan's theory of the impact of media on attitudes and behaviors.

A major problem with most research aimed at analyzing each of these four theoretical positions is that they are seldom, if ever, analyzed in a comprehensive model which allows for the control of each theoretical position. In this study a complete model is utilized which allows for 
analyzing the influence of each of the factors on the suggested attitudes and behaviors through a main effect or an interactive effect.

Through empirical analysis it is possible to test the influence of each of the positions while holding constant the other three perspectives. In this manner this study should help clarify which theory, if any, when empirically evaluated, has the greatest influence on the attitudes and behaviors selected. 


\section{REVIEW OF LITERATURE}

Sociologists who have studied the development of urbanism have found that urbanization is correlated with particular behaviors and attitudes among residents of cities. Among the behaviors assumed to be associated with urbanization are: 1) less contact with extended kin, 2) increased involvement in voluntary organizations, 3) smaller number of children, and 4) voting patterns tied to specific interests (Wirth, 1938). Attitudes that have been proposed as being associated with urbanization include: 1) alienation and anomie. Alienation is defined by Seeman as powerlessness and social isolation (along with three other forms of alienation, although in this analysis only powerlessness and social isolation are tested) (Seeman, 1959). Anomie is a condition described by Durkheim as, "a state of normlessness" within the structure of the social system (Abrahamson, 1980, pp. 190-91), but individuals are seen to suffer the consequences psychologically. Alienation and anomie are similar in that they both indicate a feeling of isolation from the greater society.

It is important to define urbanization to clear up any ambiguous meanings. Hope Tisdale in the article, "The Process of Urbanization," gives a simple definition of urbanization. "Urbanization is a process of population concentration" (Tisdale, 1942). In contrast, urbanism is 
defined by Louis Wirth as the way of life of urban dwellers (Wirth, 1938). The major difference between the two definitions is that Tisdale sees urbanization as a demographic process while Wirth sees urbanism as a psychological phenomenon, an individual reaction to the process of growth and concentration of population.

In summary, several theories have been proposed to explain the assumed behaviors and attitudes believed to be found in urban populations. The first is demographic concentration, i.e., population size. The second explanation is based on the everyday structural conditions of the society. The third emphasizes individuals' exposure to the symbolism of urban life via the electronic media. A fourth alternative explanation is that it is the individual's position within the social class system that influences attitudes and behavior.

\section{DEMOGRAPHIC CONCENTRATION}

Several sociologists have seen the demographic concentration of the city as generating behaviors that are significantly different from those found in rural areas. Behaviors such as less kinship contact, fewer children, increased involvement in specialized organizations, and voting behavior aimed at specialized interests are proposed as being influenced by high population concentration and heterogeneous population mixes (Abrahamson, 1980).

While Wirth and others see socio-psychological conse- 
quences of living in large, dense and heterogeneous environments, research on large, dense, and rapidly growing third world cities provides contradictory evidence. Seligson and other third world analysts have been struck by the similarities in attitudes and behaviors between residents of the cities and of the rural villages. The migrant networks and frequency of continuing contact between city $d w e l l e r s$ and their village kin are believed to be the cause for these similarities (Seligson, 1977).

Included in the argument of those who support the demographic theory is the belief that urban orientations are moving toward utilitarian relationships. Research conducted by Coleman and Neugarten suggest that social class is the determining variable in involvement in voluntary organizations, not, as Wirth believed, urbanism (Coleman and Neugarten, 1971).

Studies have also indicated that close personal relations do exist in urban environments (Gans, 1962; Meadows and Mizruchi, 1969; Whyte, 1955; Young, 1972). At the same time, many ethnographers of rural and peasant societies report great interpersonal distance and hostility among individuals in non-urban environments (Banfield, 1958; Whyte, 1955). These studies show a positive relationship between rural environment and alienation. They point out that urbanization is not the cause of alienation among residents.

An alternative explanation is that social class could 
be the causal variable, not urban living. Social class is perceived to be the causal variable because, as Merton explains, "cities have historically been associated with great expectations. Those individuals at the lower end of the class system find it difficult to reach these high expectations; therefore they become alienated and anomic" (Abrahamson, 1980, pp. 201-2).

In contrast to the demographic hypothesis which suggests that kinship contact decreases due to high mobility and urban living, studies conducted in India have shown that, "no changes in family size developed nor was a tendency toward nuclear families developed as urbanization increased" (Abrahamson, 1980).

The demographic explanation of behaviors associated with urbanization has many flaws. First, as studies have shown, urban dwellers do not necessarily have less extended kinship contact. Second, voluntary involvement in groups has not been shown to be caused by increased interaction in a highly populated area. Research has shown, rather, that social class is a better determinant in predicting involvement in voluntary organizations. Empirical evidence has shown that family size does not always decrease with increased urbanization. Finally, findings have not supported the view that urban dwellers have less personal attitudes toward neighbors and friends. To clarify these conflicting views this study proposes to analyze the independent influence of population concentration on atti- 
tudes and behaviors assumed to be urban.

\section{THE STRUCTURE OF EVERYDAY ACTIVITIES}

An alternative to the demographic explanation of what causes variation in attitudes and behaviors was proposed by Emile Durkheim. His is a structural argument which sees segmentalized roles of individuals in an urban industrial society as influencing alienation among individuals.

Durkheim was interested in how a complex society was integrated. According to Durkheim, when a society is integrated each of its specialized parts has its own place (Durkheim, 1951). Instead of seeing the concentration of population as causing alienation he sees the diversification of occupations and social roles as creating anomie and alienation. He viewed increased interaction and communication as creating a need for specialization. This specialization is seen as occurring in occupational realms as well as personal realms. This position assumes that diversification forces individuals to interact increasingly on a secondary group relationship level. With the loss of primary group relationships the group can no longer validate moral codes. The loss of control over individuals by the group creates individuals whose aspirations, according to Merton and other structural functionalists, are stimulated, yet who have no institutionally legitimated way of attaining these unleashed wishes or desires. This encourages disequilibrium within the social system (Etzioni, 1973). The consequences are 
despair, depression, crime, alienation, anomie, and in the extreme case suicide. According to this position the possibility of alienation and anomie is greater in an urban environment than in a rural one because of the increased individualism and specialization which occurs as work for pay, specialized occupations, and careers begin to displace the family as the primary arena within which behaviors occur.

Research conducted on alienation and anomia has not supported this hypothesis. Anomia is indexed by a scale developed by Leo Srole to measure the personal reactions to the structural conditions of anomie as described by Durkheim. Studies conducted on rural and urban areas have shown that levels of anomia are fairly low in urban areas while in the rural areas the anomia level was relatively high (Greer, 1962; Mizruchi, 1969).

The structural conditions explanation of the feelings of powerlessness and social isolation of individuals in society has not been supported by empirical findings. While theorists see the diversification and specialization in society as creating anomic and alienated individuals, research has shown that specialized occupations associated with urban environments are not the causal factor (Coleman and Neugarten, 1971). As social theorists have indicated, urbanization is associated with increased diversification in the work force. To support their structural hypothesis a higher level of alienation and anomia would be expected in 
urban environments. Yet, the opposite has been indicated by empirical findings. In an attempt to clarify these contrasting explanations and findings this study proposes to examine the independent influence of occupational diversification on attitudes and behaviors considered "urban." The extent to which diversification in the work force covaries with demographic concentration of population has been treated as an empirical question rather than as an unquestioned assumption.

EXPOSURE TO THE SYMBOLISM OF URBAN LIFE VIA TELEVISION

A third view of the urban world has been developed by Marshall McLuhan, a journalist who studied the impact of media upon society. In contrast to the view of the demographic theorists, McLuhan believed the advent of electronic media has created a global village of ever contracting size (McLuhan, 1969). He also disagrees with those sociologists who propose that it is the structural condition of the society which creates individuals who have only minor or secondary contact with one another. According to McLuhan:

"The speed of information movement in the global village means that every human action or event involves everybody in the village in the consequences of every event. The new human settlement in terms of the contracted village has to take into account the new factor of total involvement of each of us in the lives and actions of all" (McLuhan, 1969, p. 42). 
In McLuhan's analysis of the global village the problem of settlement is that of the extension of consciousness itself and the maximization of opportunities for learning. He sees the problem of settlement in the mechanical age as one of the individual trying to act as far as possible without involving himself in the lives of others. He theorizes that the industrial age gave us a kind of theater of the absurd, in which people trained themselves to act without reacting, to pride themselves on their power of detachment and non-involvement. Our current age, according to McLuhan, is the age of implosion, of inclusive consciousness and deep personal involvement. He believes the current crisis in human settlements arises because of a clash between these opposed forms of culture and technology (McLuhan, 1969).

In summary, McLuhan sees the increased knowledge of the world as influencing people by increasing their stimulation through constant interaction with value systems that are unlike their own. Whereas in the past individuals were somewhat isolated and had little knowledge of people in other life circumstances, the present explosion of information over-stimulates the individual. Through this overstimulation individuals are now found to be overly concerned with other individuals and feel isolated and alienated over their loss of control over their own life.

The clash between the past non-media oriented world and the present media oriented world has brought individuals 
to the point of not being able to separate themselves from what they see and hear through the electronic media. Through this constant awareness of the rest of the world, the individual is placed, according to McLuhan, in a position of being deeply involved with other individuals whom the television watchers cannot or feel they cannot influence. The results are alienation, anomia, and rebellion against involvement.

Janet Abu-Lughod also sees technology as impacting on relationships in society. Her hypothesis is that this new technology creates tertiary relationships, unlike McLuhan's primary relationships, where the isolation of different communities within urban regions promotes role and life style stereotyping via perceptions created by the mass media, particularly television. She believes that many people behave towards others as if these stereotypical perceptions were correct (Berry, 1973, pp. 58-9).

These two views of how the exposure to the symbolism of urban life impacts on attitudes and behaviors of individuals have not been empirically analyzed. While Abu-Lughod sees isolation and stereotyping as the consequences of exposure to mass media, McLuhan sees total involvement in everyone's lives resulting in alienation, anomie, and rebellion against involvement because of the constant exposure to the mass media. 
The placement of individuals within the economic system has been believed to be associated with how these individuals behave and the attitudes they hold (Coleman and Neugarten, 1971; Wright and Perone, 1977). Robert Rothman, in Inequality and Stratification in the United States (1978), calls this placement social class. He defines social class as, "aggregates of people who occupy a similar position in the economic system of an industrial society" (p. 146). In his analysis of social class and life chances and life styles Rothman shows that life styles do indeed differ among classes. For example, he explains that marital stability is greater for those in the upper classes, and voting behavior differs drastically among classes. His findings indicate that in the 1972 election $46 \%$ of those in the lower classes voted while $79 \%$ of the upper class voted (p. 192).

The level of exposure to the symbolism of urban life styles via television was also found to differ significantly by class. The average minutes per night viewed by adults in the lower class was 180, while the upper class adults only watched an average of 16 minutes per night (p. 192). Self derogation, a feeling of powerlessness and alienation, was also found to differ among classes. Rothman's analysis uses a high percentage score to indicate a high level of alienation and powerlessness. The lower 
middle class and the working class averaged a $53.5 \%$ selfderogation score while those in the upper class averaged a score of $22 \%(p .192)$.

These findings suggest that it may not be the physical environment, the structure of everyday activities, or the exposure to the symbolism of urban life via television but the social placement of the individual within the economic system which influences these specific attitudes and behaviors. To clarify these findings this analysis proposes to conduct an inquiry by designing and employing a model which incorporates all four factors.

\section{SUMMARY}

The contrasting explanations of what causes specific behaviors, i.e., loss of kinship contact, smaller families, higher involvement in community organizations, and greater involvement in voting, must be analyzed together in a complete model. If we are to develop clear theoretical propositions on the impact of demographic concentration, the structural conditions of society, social class, and the exposure to the symbolism of urban life via mass media, each position must be analyzed empirically to find which, if any, has he greatest independent influence on the suggested behaviors when the others are controlled. Up to this point studies have shown mixed support for the theoretical contentions of the physical environment, structural conditions, and social class arguments. In fact, studies provide 
contradictory evidence. A major problem which remains is to determine to what extent these theories are interrelated; without taking this into consideration spurious findings may result.

As for the cause of specific attitudes such as alienation and anomia, research conducted in rural and urban areas has also not supported the specific theoretical assumptions which state that urbanization causes feelings of isolation and powerlessness. In fact the empirical evidence suggests that it is not urbanization but social class which is the influencing condition. Because of these findings this study is aimed at empirically evaluating the independent influence of each of the four theoretical explanations which suggest causal effects on specific attitudes and behaviors.

This evaluation is important because it includes all four positions in social science research to help correct simplistic theorizing. By using a complete model it will be possible to check empirically whether any or all of the theories do statistically influence the assumed behaviors and attitudes. 


\section{METHODOLOGY}

The data used in this study were provided by the National Data Program for the Social Sciences and produced by the National Opinion Research Center at the University of Chicago, Chicago, Illinois (N.O.R.C.). The utility of using N.O.R.C. data is the national perspective achieved. The N.O.R.C. survey is an independently drawn sample of Englishspeaking persons 18 years of age or over, living in noninstitutional arrangements within the continental United States (N.O.R.C. Cumulative Code Book, 1972-80). The survey uses a full probability sample.

In using a stratified, full probability sample to analyze the independent influence of the physical environment, structure of everyday activities, social class, and exposure to the symbolism of urban life, it is possible to estimate the probable success of selecting a sample of the population which accurately describes the total population. In this study the total population is that of the continental U.S. The use of multistage area probability sample such as N.O.R.C. will decrease the possibility of sampling error, and will reduce the possibility of consciously or unconsciously biasing the sample. Also the size of the N.O.R.C. data base, 1468 in 1980, allows for greater likelihood of selecting a sample which accurately estimates characteristics of the universe (Kerlinger, 1979). 


\section{LIMITATIONS OF DATA SET}

This study is intended as an examination of some of the predominant assumptions in urban sociology. There are, of course, important limitations in making generalizations about specific theoretical questions when the data are derived from secondary data sets. It is important to point out that the N.O.R.C. survey is intended as a general social science instrument and was not developed to specifically treat the question which this study addresses: namely which of the four factors analyzed has the greatest influence on behaviors and attitudes that are assumed to be associated with modern urban living?

\section{STATISTICAL METHODS}

The statistical methods used in this study are crosstabulation and analysis of variance. Cross-tabulation was selected because of its straightforward simplicity in examining bivariate relationships. The use of analysis of variance, the primary procedure used, was selected because of the nature of the problem being investigated and the nature of the data base at hand. It can be used to evaluate the validity of competing theoretical perspectives.

As an analytical tool, analysis of variance avoids the problem of multicollinearity existing in multiple regression analysis and allows for examination of the independent effects of one theoretical variable upon a presumed attitu- 
dinal or behavioral consequent by literally removing variation in such consequents due to effects of competing theoretical variables. It allows us to ask the question, "If we allow competing arguments to explain all the variance in a consequent that they can, is there any additional variance which can be attributed to the independent effect of another argument?" This technique also allows an examination of the extent to which various combinations of arguments may be involved in the explanation of phenomena through direct examination of interaction effects. As an inferential tool, analysis of variance has the added advantage of being more robust than multiple regression regarding assumptions of the model being employed.

Because the data base available is a well designed and executed probability sample of the adult American population, it is possible to use inferential procedures to test the validity of these theoretical arguments for the American population at large rather than just describe the particular sample statistics which we know are subject to sampling error. The criterion for validation of a particular theoretical argument, or combinations of arguments, is whether or not a specific theory, or set of theories, is able to independently account for (or explain) any variation in selected attitudes and behaviors in American society when other theoretical arguments are taken into account statistically. The F test for significance of main effects and interaction effects allows us to evaluate such arguments with a known 
probability of error. The existence of significant effect occurs to the extent that variation in attitudes and behaviors between categories of a theoretical explanation exceeds expected variation within categories, after variation due to competing explanations have been statistically removed. The inferential conclusions given apply to the American population at large regarding whether or not a relationship exists between the theoretical variables posited as causes and the attitudes and behaviors presumed as consequences.

\section{OPERATIONALIZATION OF THEORETICAL CONSTRUCTS}

\section{Demographic Concentration}

Louis Wirth (1938) saw three differing conceptualizations of urbanism. Of the three conceptualizations this study has used population size as the defining characteristic of an area. Wirth saw each of the three conceptualizations as exerting independent influence on social structure and attitudes (Abrahamson, 1980). He saw population concentration as precluding intimate contacts. Because of the impact of Wirth's perspective on urban sociology, this study has utilized population size as the primary independent variable to test the effect of demographic concentration on specific attitudes and behaviors.

In analyzing the impact of demographics, i.e., population concentration, on behaviors and attitudes that are assumed to be cosmopolitan, N.O.R.C. allows for operational- 
ization of size of place ranging from a large central city (over 250,000 ) to open country within a larger civil division, e.g., township (Appendix A). The comprehensive breakdown of size of community allows recoding into larger more generalizable categories. In this way it was possible to measure the independent influence of population concentration on the specific attitudes and behaviors. While Wirth and others have not specified what the population of an area must be to be considered urban, this study will use the Department of Commerce, Bureau of the Census S.M.S.A., standard metropolitan statistical area, as the breakdown for urban and non-urban. An S.M.S.A. is defined as a metropolitan area around and including a central city of 50,000 or more (N.O.R.C. Cumulative Code Book, 1972-80). This distinction between metropolitan and non-metropolitan is given empirical validation by its ability to explain variation in selected attitudes when considered by itself -- that is without controlling for correlates of this variable.

\section{Structure of Everyday Activities}

Emile Durkheim saw the division of labor as intensifying with increased industrialization and urbanization. Again, the increase in population size is a major force for Durkheim and Wirth and can be seen as influencing both urbanism and the division of labor.

To measure the division of labor and the increased specialization of the sample being analyzed in this study, 
both spouses working was used. In Abrahamsons' analysis of Durkheim he explains that Durkheim felt that when a complex society is properly integrated, each of its specialized parts has its own place, and the arrangement of the parts are known to everyone (Abrahamson, 1980). As population size increases specialization also increases making it more difficult for each part to know each other part's location. This non-integration pattern is seen by Durkheim as occurring with an increase in specialization. He sees this diversification as creating malintegrated individuals. This study uses spouse working as a measure of this diversification and specialization within an urban society. Spouse working refers to whether or not both individuals in a two adult household have jobs outside the home (Appendix A). In this manner it should be possible to focus on this particular everyday activity, both members of household working, to test for the independent influence of the structure of everyday activities on the specific attitudes and behaviors. In analyzing the influence of the structure of everyday activities of individuals on attitudes and behaviors assumed to be associated with a high level of specialization this study should help clarify whether or not variation in selected attitudes and behaviors can be attributed to the structure of everyday activities of individuals. It is important to note that Durkheim was not specific in what he called "structural integration" of society. Because Durkheim saw diversification as breaking down the integra- 
tion of systems and creating malintegrated individuals, this study will focus on the family, the primary integrating force, as the focus for the operational definition for the diversification of everyday activities.

Exposure To The Symbolism of Urban Life Via Television

The exposure of individuals to the lifestyles of people far removed from their own personal environment has been seen by several sociologists and journalists as having an influence on attitudes and behaviors of individuals (McLuhan, 1966, 1967; Abu-Lughod, 1961; Toffler, 1970). McLuhan, a journalist and philosopher, sees the bombardment of information as transforming society and individuals. He sees this change as being brought about by the "implosion" of media, i.e., television, and creating a new environment as well as new individuals. These individuals, according to Mcluhan, are involved in everyone else's lives and have lost the privacy in their lives that was a predominant characteristic of individuals before the media explosion (1967). To measure the independent influence of the exposure to the symbolism of urban life the number of television hours an individual watches per day will be the operational definition of this theoretical position. The question provided by N.O.R.C. is: "On the average day about how many hours do you personally watch television?" (Appendix A). The hours were recoded into two categories: 1) four hours per day or less = little t.v. watched, 2) over four hours per day = 
great deal of t.v. watched.

While it is important to emphasize that the quality of time spent watching television can affect the influence of the medium, it is difficult to empirically evaluate the quality of time spent watching television. The actual hours the respondent reports watching television will be used to measure how much exposure to the symbolism of urban Iife an individual receives.

\section{Social Class}

Social class has been proposed as affecting individuals in the way they interact in society (Wright and Perone, 1977; Inkeles, 1960). Inkeles found that higher status individuals were found to be happier than those of lower status (1960). Social class has also been seen as affecting voluntary organization affiliation and attitudes of alienation and anomia (Key, 1965; Fischer, 1973). Wright and Perone feel that social class strongly influences behaviors, and some of these behaviors are similar to those expected by urban sociologists (1977). In their argument Wright and Perone use the classic Marxian approach to social class, that of proximity to the means of production. In their analysis they used a breakdown of: 1) Employers, 2) Managers, 3) Petty Bourgeoisie, and 4) Employees. The N.O.R.C. data only enable a breakdown of social class by: 1) Self employed, or 2) Employed by someone else (Appendix A). This distinction should give some insight into the 
basic premise of Marx, which is that one's status within society dictates one's attitudes and behaviors. 


\section{FINDINGS}

Four theories of urban sociology were examined by using cross-tabulation and analysis of variance. The intended purpose of this study is to explore and clarify the influence of each of the theoretical positions on attitudes and behaviors that are believed to be associated with urban living.

The predominant finding of this study is that the number of hours per day an individual watches television accounts for variation in attitudes and behaviors much better than the other conceptualizations of "urban." It influences, through a statistically significant main effect: 1) Anomia, 2) Individual life satisfaction; and 3) Membership in professional organizations. When the other three theoretical positions are controlled, the amount of exposure to the symbolism of urban life an individual receives through watching television is involved in independently influencing three of the ten attitudes and behaviors analyzed. Exposure to the symbolism of urban life is also involved in interaction with the other theoretical perspectives in affecting; 1) number of children; 2) membership in political organizations; 3 ) trust of other individuals; and 4) individual happiness. There were no interactive effects upon the selected attitudes and behaviors which did not involve media exposure. 
The structure of everyday activities, i.e., whether or not spouse works, was found to have statistically significant main effects upon: 1) Anomia2, and 2) Elderly living with children. Although much less involved with the ten selected attitudes and behaviors than media exposure, it was second in utility in explaining them. It was also involved in two interactions. Social class as defined as self employed or working for someone else exhibits a statistically significant main effect only upon voting in the 1976 election and is involved in three interactions.

Demographic concentration, living within an S.M.S.A. or not, shows no significant main effects and interacts with the other perspectives in influencing only: 1) Membership in political organizations; 2) Trust of other individuals; and 3) Individual happiness.

Table I shows the relationship between each of the seven attitudes selected for analysis and the four theoretical perspectives presumed to explain why people differ in these attitudes. Table II provides the relationships between the four selected behaviors and their presumed theoretical influences. The extent to which a given theoretical perspective accounts for a given attitude or behavior, when the other three perspectives are ignored, can be determined by a comparison of the magnitude and direction of the differences between each pair of percentages in a given row of the tables. These bivariate relations are provided here 


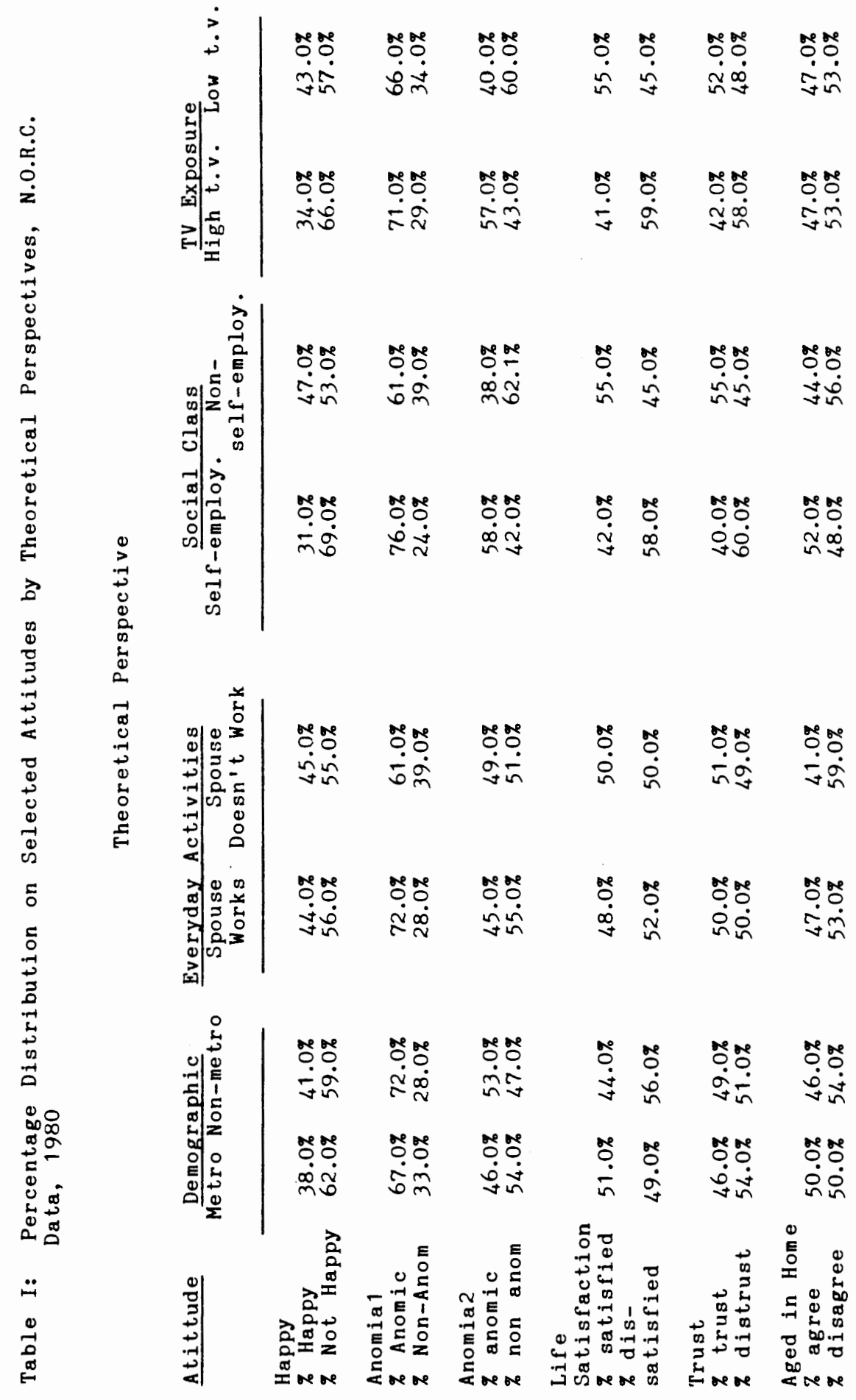




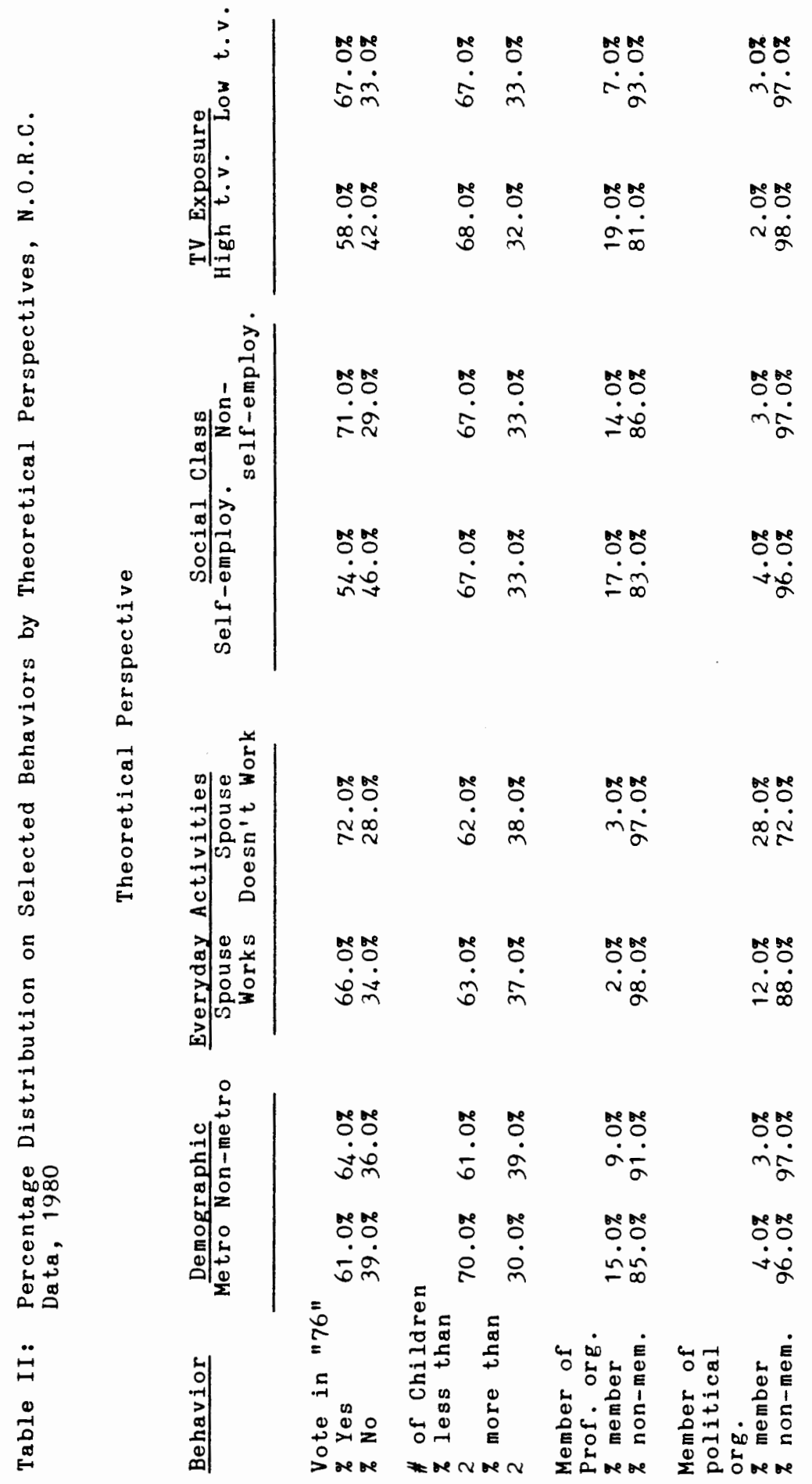


as replicated evidence for past studies which have argued the utility of a given theoretical perspective while ignoring, or at least failing to statistically control for, alternative theoretical explanations for "urban" attitudes and behavioral patterns.

Table III provides a summary of the independent effects of the four theoretical perspectives upon all ten selected attitudes and behaviors as well as all combinations of theoretical perspectives (interaction effects) which significantly affected these presumed consequences of "urban" living. The detailed four-way analyses of variance which are summarized here are provided in Appendix $B$. Unlike the bivariate relations described in Tables I and II, the relations summarized in Table III derive from a complete model where all four theoretical perspectives are considered simultaneously. The numbers in the body of the table are the likelihoods of observing a relationship as strong as or stronger than observed (the significance of $F$ ), when the other three perspectives have been controlled, if there were no relationship in the adult American population. Only relations significant beyond the .05 level are indicated and only those interactions which were significantly related at the same level are shown. The findings are organized, by refering to Table III, in order of their capacity to independently explain variation in selected attitudes and behaviors. 
Table III: Significance Level of $F$ for Comparison of Four Theoretical Perspectives in Explaining Variation in Selected Attitudes andBehaviors. 4 Way Analysis of Variance, N.O.R.C. Data, 1980

Theoretical

Perspective

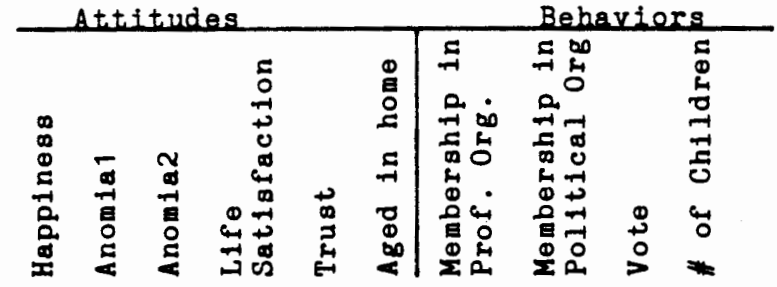

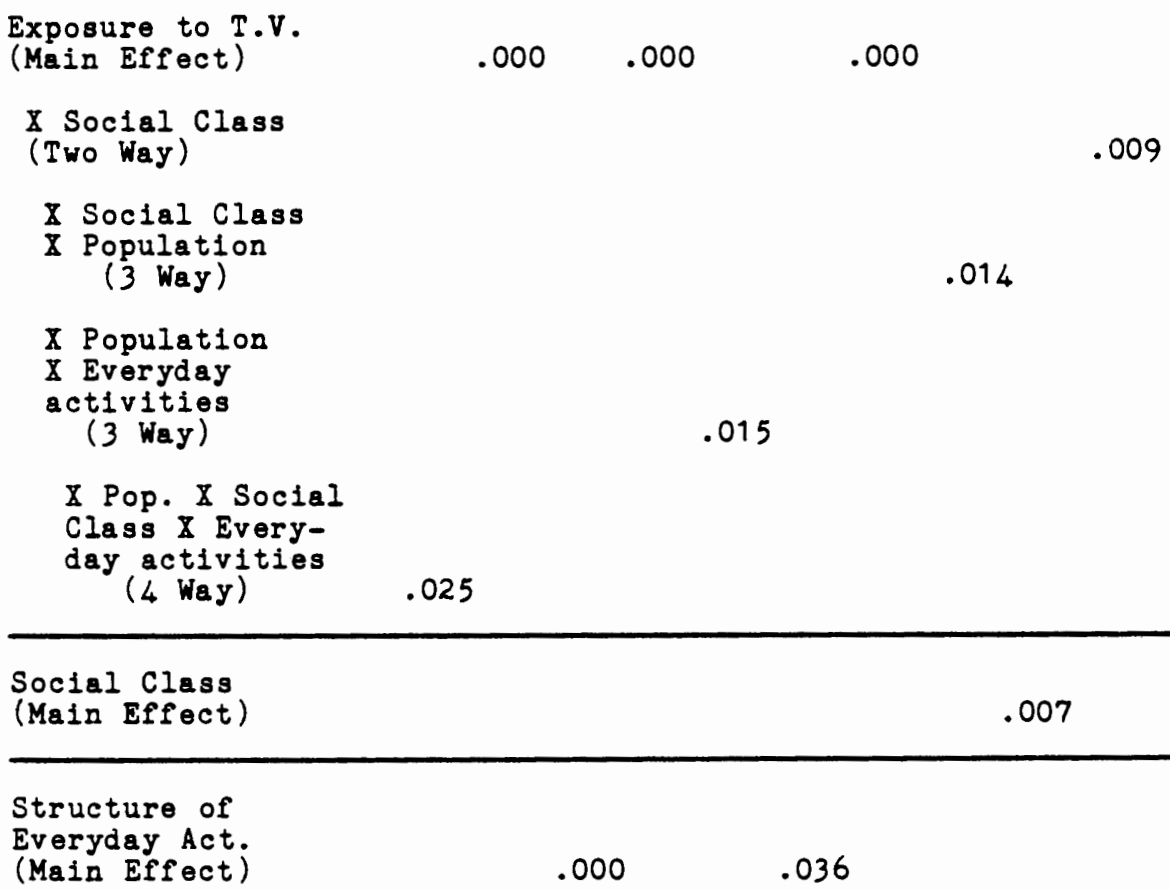

Social Class

(Main Effect)

Structure of Everyday Act. (Main Effect)

Physical Environment (Main Effect) NONE

Anomial is; "It's hardy fair to bring a child into the world the way things look for the future."

Anomia2 is; "In spite of what some poople say, the lot (situation/condition) of the average man is getting worse, not better." 
THE UTILITY OF EXPOSURE TO THE SYMBOLISM OF URBAN LIFE

Anomia, the internalized personal feelings of individuals associated with anomie, was selected as an attitudinal variable to represent Durkheim's position which assumes that as individuals become alienated and less integrated into their society they become less satisfied with their lot in life. By selecting the question, "It's hardly fair to bring a child into the world the way things look for the future," (Appendix A), it was possible to test the variation among the population in anomic feelings. The response to this question is referred to hereafter as anomia1.

The percentages found by cross-tabulation of anomial with each of the theoretical perspectives differ significantly (alpha $=.05$ ) for structure of everyday activities and for social class. The percentages are not significantly different between the categories of the demographic and exposure perspectives (Table I). However, when all four perspectives are considered simultaneously by using four way analysis of variance, only exposure to the symbolism of urban life was found to be involved in a statistically significant influence on anomial (Table III).

The results of this analysis of anomial do not lend support to the arguments presentd by Perone and Wright, Wirth or Durkheim but suggest that the exposure to the symbols of urban life are involved in a relationship with feelings about bringing a child into the world. Although, 
as Table I shows, these feelings appear to be related to activity patterns and social class, these relations are spurious when the other two perspectives are taken into account through four way analysis of variance.

When individual Iife satisfaction was analyzed by using cross-tabulation, percentage satisfied was found to differ by the number of hours an individual watches television and by social class (Table I). Selection of life satisfaction as an attitudinal attribute was based on the Wirth assumption that increased interaction and specialization create individuals who deal with one another in fragmented ways instead of those whole relationships believed to be found in rural areas (1933).

McLuhan also saw the life satisfaction of individuals as influenced by increased stimulation but not from densely populated living arrangements but through intensive exposure to information via the television (1967). He saw the influence of media as alleviating the isolation and privacy of individuals and replacing this with a complete knowledge system of all the individuals within the society. This can lead, according to McLuhan, to a state of transition from one tradition, the pre-media period, to the high media exposure period of today which results in a loss of life satisfaction because of over stimulation (1967).

When a complete model was used, life satisfaction, (See Appendix A for Question), as reported by the respondents, was influenced only by the number of hours an 
individual watches television and was statistically significant beyond the .001 level (Table III). The affect of social class apparent in Table $I$ is spurious.

It is quite evident that, when the other three theoretical positions are controlled, the statistically significant influence of number of television hours watched per day remains. This suggests that a relationship exists between the amount of exposure an individual receives from the symbols of urban life through watching television and the individual's level of life satisfaction. The other three perspectives show no independent or interactive involvement with this variable.

Membership in professional organizations was found to be related through a statistically significant main effect, with the exposure to the symbolism of urban life (Table III). Membership in voluntary organizations has been proposed as being influenced by: 1) size of place; 2) the structure of everyday activities; 3) social class; and 4) exposure to media.

Involvement in voluntary organizations was selected as a behavior because Wirth saw urbanites as becoming involved in a variety of specific organizations to fulfill specific needs that could not be met by a single organization (1933). Durkheim also saw specialization and diversification as influencing the behaviors of individuals through increased involvement in secondary associations. He also felt that with the increase in specialization in urban areas indivi- 
duals would begin interacting in a variety of social circles to fulfill their needs (1951).

In looking at the percentages provided by cross-tabulation (Table II), we see that individuals living in urban areas are slightly more likely to be involved in professional organizations. It should be pointed out that according to the cross-tabulation analysis an individual who watches more than four hours of television per day is $11.8 \%$ more likely than those with less watching time to be involved in professional organizations (Table II). When analysis of variance is used, membership in professional organizations is still found to be influenced by the amount of exposure to the symbolism of urban life, but the effect of size of place is explained away (Table III). This suggests that to account for the differential membership in professional organizations, considering the four theoretical arguments of "urban" it would be important to include only the influence of mass media.

Membership in voluntary organizations as analyzed using membership in political organizations was found to be influenced by a three way interaction of: 1) exposure to the symbolism of urban life; 2) social class and; 3) size of place (Table III). These findings suggest that membership in political organiztions is influenced by an interaction effect of the Wirth, Perone and Wright, and McLuhan positions while membership in professional organizations is influenced by a main effect involving just the exposure to 
the symbolism of urban life. What this indicates is that the assumption that membership in voluntary organizations is a general category is not supported by empirical evidence. Political organization membership is apparently a more complex phenomenon than is membership in voluntary organizations such as professional organizations.

Family size as suggested earlier in this study has been proposed as being influenced by: 1) size of place of residence; 2) the structure of everyday activities; 3) social class and; 4) exposure to the symbolism of urban life (Wirth, 1938; Durkheim, 1951; Perone and Wright, 1977; and McLuhan, 1967). In the analysis using just percentages without controlling for the other three theoretical positions, population size shows the most dramatic differences in responses to the question, "How many children have you ever had?" (Appendix A). Of those individuals living in urban areas, $10.5 \%$ more of those individuals had two or less children (Table II). If this was the only analysis used, Wirth's position would be supported. Yet when analysis of variance is used, a two way interaction between social class and exposure to urban life via television is the only statistically significant influence upon the number of children an individual has (Table III). The two way interaction is statistically significant at the .009 level (Table III).

These findings indicate that it is not the structure of everyday activities of an individual (Durkheim perspec- 
tive) or demographic concentration (Wirth perspective) that influences family size. Instead a two way interaction involving the individuals distance from the means of production and the amount of exposure to the symbolism of urban life via television is found to influence family size.

The trust an individual has of other people was found to be influenced by a three way interaction effect involving: 1) exposure to the symbolism of urban life; 2) population concentration; and 3) the structure of everyday activities (Table III). Wirth and Durkheim saw population increase as influencing increased specialization which removed the individual from primary interactions. This leads to feelings of alienation and mistrust of other people. In this analysis alienation was placed in psychological terms such as individual trust and happiness (See Appendix A for questions).

When cross-tabulation is used to analyze the relationship among each of the four theoretical positions and trust, it was found that people's trust of other individuals was related to social class and the exposure to the symbolism of urban life (Table I). Fifteen per cent more respondents who worked for someone else reported that they trusted other people than those who were self employed, while $9.8 \%$ more of those individuals who watch less than four hours of television per day reported that they trusted people (Table I). 
When analysis of variance is used the influence of size of place, the structure of everyday activities and the exposure to the symbolism of urban life all interact on the variable trust. This three way interaction is statistically significant at the .015 level (Table III). These findings indicate that neither the Durkheim nor the Wirth perspective alone allows for specific explanation of feelings of alienation because they do not take into consideration the exposure to the symbols of urban life as presented by the mass media, primarily television.

Individual happiness, an internalized dimension of alienation, was found to be influenced by a four way interaction involving all four theoretical positions (Table III). This is the most complex relation found in this analysis and underscores the general confusion in the literature in attempting to account for different levels of expressed happiness.

When using zero order correlates the theoretical implications of Durkheim and Wirth seem to be supported by the findings (Table I). The percentages show a $2 \%$ difference between those individuals living in an urban environment and a rural environment in their levels of happiness. In Durkheim's analysis he sees individuals' everyday activities as influencing their self worth. By selecting the available question from N.O.R.C. this study was able to probe this dimension of alienation (See Appendix A for question). 
Individual levels of happiness have been analyzed by sociologists of the Marxist school, and in this analysis when using bivariate relations happiness is seen to differ by employment status. Respondents indicated that their self reported level of happiness was related to whether they worked for themselves or someone else. Of those respondents who worked for someone else $47.1 \%$ of those individuals reported that they were happy with their lives compared to $30.9 \%$ of those individuals who worked for themselves (Table I). These findings do not lend support to the Marxist argument because they would expect to find the working class reporting a higher degree of alienation.

McLuhan's point that exposure to television may create a conflict between the old culture and the new one of media "implosion" receives some support with the bivariate relations because $8.6 \%$ more individuals who watch less than four hours of television per day reported they were happy with their life (Table I) than those who wat ched more that four hours a day.

When analysis of variance is utilized in this analysis a four way interaction statistically significant at the .025 level lends support to the zero order findings that all of the four theoretical positions are involved in influencing this particular dimension of alienation. To develop a clearer picture of the relationship between alienation and "urban environment" all four of the theoretical positions must be taken into consideration simultaneously. 
THE UTILITY OF THE STRUCTURE OF EVERYDAY ACTIVITIES

The second dimension of anomia, anomial hereafter, that dealing with the individuals' perception of their position in society, was found to be influenced by a statistically significant main effect $(p<.001)$ of the structure of everyday activities (See Appendix A for question). When analyzing the findings of cross-tabulation, anomia2 is seen to be influenced by social class, i.e., those individuals who are self employed or work for someone else. One fifth (19.9\%) more of those individuals who are self employed reported that they agreed that the situation of the average man is getting worse (Table I). Exposure to the symbolism of urban life via television was also shown by zero orders to influence anomia2. Almost $20 \%$ more of those individuals who watch over four hours of television per day reported that they felt the situation of the average man is getting worse (Table I). But when four way analysis of variance is performed, anomial is found to be influenced only by a main effect of the structure of everyday activities, which is statistically significant beyond the .001 level (Table III). These findings suggest that when the other three theoretical positions are controlled for, it is only the structure of everyday activities as defined as spouse working or not that explains variation in this particular dimension of anomia. Again these findings emphasize that anomia as a broad category must be analyzed by looking at 
each dimension separately (Seeman, 1959).

Attitudes toward the importance and place of the family have been seen as being associated with the structure of everyday activities (Durkheim, 1951). The findings of analysis of variance support this position. The structure of everyday activities was found to be statistically significant $(p=.036)$ in influencing attitudes toward the elderly living in the child's home (Table III).

The zero order correlates also show a relationship between everyday activities and believing that it is a good idea to have the elderly live with their children (Table I). of those individuals where the spouse works, $47 \% \mathrm{felt}$ that it is a good idea to have elder family members live with their children, compared to $40.6 \%$ of those whose spouse doesn't work. According to the Durkheim perspective, as technology increases, diversification in employment and family functions occur, and family importance and structure change (1951). To test whether or not the structure of everyday activities does indeed influence attitudes concerning the family the question, "As you know, many older people share a home with their grown children. Do you think this is generally a good idea or a bad idea?" was selected (N.O.R.C. Cumulative Code Book, 1972-80).

The combination of findings, cross-tabulation and four way analysis of variance, lends support to the Durkheim position, although the direction of the influence is opposite of what would be expected by Durkheim. Instead of 
those individuals who live in a one career family believing that the parent should live with grown children, it is those individuals who live in a two career family that feel it is a good idea. These findings suggest that to understand the changes in attitudes toward the family the structure of everyday activities must be taken into consideration.

\section{THE UTILITY OF SOCIAL CLASS}

Individual voting behavior has been suggested by Wirth as being influenced by the size of place of residence (1933). Wirth saw urbanites as becoming self centered and aiming for personal goals because of the increase in secondary interactions while living in a large place, while Alex Inkeles saw individuals as being shaped by the nondemographic social institutions in which they live (1960). Wirth felt that voting behavior would be influenced by whether or not an individual lived in an urban or rural area which differs from Inkeles' belief that it is the social institutions, such as social class, that would be more likely to influence individual behavior.

When analyzing voting behavior by cross-tabulation (Table II), social class is indeed related to voting behavior. of those individuals self employed, $53.6 \%$ voted in 1976 while of those individuals who worked for someone else, $70.9 \%$ voted. The $17.3 \%$ difference lends credence to the social system position but it is opposite of the expectation of the Marxists. They would expect to find the elite voting. Yet, 
social class is not the only theoretical position that shows a dramatic difference in responses to the question concerning voting in 1976 (See Appendix A for question). There is a $10.1 \%$ difference in voting when analyzed by the number of hours of television an individual watches per day. Those who watch less than four hours per day were more likely to vote (Table II).

When social class is analyzed controlling for the other three theoretical positions using analysis of variance, only social class is found to be involved in a statistically significant main effect upon voting behavior (Table III). The main effect is statistically significant at $\mathrm{p}=.007$.

This finding lends support to the social class position which suggests that it is the placement of the individual in the social system that influences their voting behavior. Yet the relationship is in the opposite direction of that expected by the Marxist school of thought. It is quite possible that these individuals who are voting may be socialized through involvement in labor oranizations, etc., to vote and therefore are more likely to take part in national elections. The importance of this finding is that to understand the relationship between voting behavior and theories concerning the "urban environment" social class appears to be the only perspective of the four which is relevant. 
THE UTILITY OF DEMOGRAPHIC CONCENTRATION

The demographic argument proposed by Louis Wirth was not supported by these empirical findings. The population size of an individual's particular environment was not involved in one statistically significant main effect on any of the ten attitudes and behaviors analyzed, although the size of place was involved in interaction effects on: 1) membership in political organizations; 2) trust of other individuals; and 3) happiness. These are two and three way interactions indicating that at least two of the other perspectives must be involved at the same time.

What these findings suggest is that to develop a theory which defines causal influences of living in urban or rural environments, all four theoretical positions must be included in the analysis. Demographics alone do not show the greatest influence over any of the attitudes and behaviors that Wirth suggests as being associated with an urban environment.

\section{SUMMARY}

In summarizing these findings it is important to emphasize that not one of the theoretical positions analyzed could be found to have an overwhelming influence over the attitudes and behaviors analyzed. While the exposure to the symbolism of urban life via television is found to be involved in influencing seven of the ten attitudes and 
behaviors it does not have a very strong influence as indicated by the correlation ratios reported in Appendix $B$ with the detailed analysis.

The second most important theoretical perspective according to the criteria of utility in accounting for variance in selected attitudes and behavior employed here, is the structure of everyday activities, followed by social class. Size of place, perhaps the most wide spread presumed influence in the urban literature, is given the least support. 


\section{CONCLUSIONS}

The findings of this study indicate that when analyzing these particular attitudes and behaviors not one of the four theories of urban sociology can explain variation among all the selected attitudes and behaviors of individuals that are assumed to be associated with urban living. Exposure to the symbolism of urban life has a significant independent effect upon three of the ten attitudes and behaviors selected. And, while it is involved in all of the significant interactions found, without the inclusion of the other theoretical perspectives it alone is not predictive of how an individual will respond to these other four questions aimed at soliciting feelings and behaviors. Although if one variable must be selected to account for the variation in attitudes and behaviors assumed to be urban, then the number of hours an individual watches television would be the most informative.

It is important to point out that this exploratory study was conducted using secondary data sources which were not intended to specifically treat the questions of this study. The bivariate analysis used was only a crude test of the theoretical positions which suggest different influences based upon: 1) demographic concentration; 2) the structure of everyday activities; 3) social class; and 4) exposure to the symbolism of urban life. Had this study included a 
cross-cultural analysis utilizing data from nonindustrialized countries it is possible that population size or the structure of everyday activities would have been involved in influencing the behaviors and attitudes that are suggested by the particular theorists. Yet, the theorists who I have selected did aim their analysis at industrial countries. The data base here was for an industrial country and did not show a great deal of influence on these attitudes and behaviors.

The ramifications of this exploratory study are varied, but the most important is the finding that when empirically evaluated and controlled for, the main theories of urban sociology do not have a great influence over these attitudes and behaviors. Population size, whether living in a metropolitan or non-metropolitan environment, was not involved in one main effect influencing the attitudes and behaviors that had been assumed to be associated with urban living .

The influence of social class, although the operational definition was crude, is limited to voting in presidential elections. While social class is involved in interaction effects on the number of children an individual has, membership in political organizations, and individual happiness, it alone does not account for any variation in attitudes and behaviors in the population studied except voting. 
Individuals involved in diversified everyday activities are influenced in their attitudes regarding anomie and whether or not the elderly should live with their grown children. Durkheim's position that diversification and specialization lead to anomic, alienated individuals is given only partial support by the findings of this study. It did effect some attitudes but none of the behaviors included.

Technological development in industrialized countries does seem to have an influence over how individuals view themselves in the society as well as how they act within the social system. As these findings show, amount of exposure to the symbolism of urban life via television may play a much more important part in how the individual acts and views himself/herself than previously suggested. Sociologists who study urban life should take into account the amount of exposure to, and possibly content of, the symbolism of urban life the population receives.

Suggestions for further analysis of the question, "What are the consequences for humans of life in urban societies?" should focus more directly upon the nature of the symbolic environment inherent in today's way of life. To clearly define the influence of advanced technology an analysis would need to include a more sophisticated measurement of this aspect of urban life than that employed here. This exploratory study was aimed at clarifying which, if any, of the four theoretical positions drawn from urban 
sociology literature has the greatest influence over attitudes and behaviors. The findings suggest that urban socio logists must make an attempt to include the increased level of technology in their analysis if they are to fully understand what causes the variation in attitudes and behaviors in a given society, particularly technologies which expand, influence, and constrain the symbolic environment to which humans are exposed. 


\section{BIBLIOGRAPHY}

Abrahamson, Mark, Urban Sociology, Prentice-Hall, Inc., Englewood Cliffs, New Jersey, 1980.

Abu-Lughod, J.L., "Migration Adjustments to The City Life: The Egyptian Case," American Journal of Sociology, 67, $1961,22-32$.

Axelrod, M., "Urban Structure and Social Participation," American Sociological Review, 21 (February 1956):14:18.

Babbie, Earl R., Survey Research Methods, Wadsworth Publishing, Inc., Belmont, California, 1973.

Banfield, E.C., The Moral Basis of a Backward Society, New York: Free Press, 1958.

Bell, W., "Anomie, Social Isolation and Class Structure," Sociometry, 20 (June 1957): 105-16.

Berry, Brian J.I., The Human Consequences of Urbanization, New York, St. Martin's Press, 1973.

Christie, R., and F.L. Geis, Studies in Machiavellianism, New York, Academic Press, 1970.

Coleman, Richard P., and Bernice L. Neugarten, Social Status in the City, San Francisco: Jossey-Bass, 1971.

Dean, D.G., "Alienation: Its Meaning and Measurement," American Sociological Review, 36 (October 1971): 872-80.

Dobson, Cynthia and Edward A. Powers, Patricia Keith, and Willis J. Gowdy, "Anomia, Self-Esteen, and Life Satisfaction: Interreltionships Among Three Scales of Well Being," Journal of Gerontology 34(4) 1979, 56972 .

Durkheim, Emile, Suicide, New York: The Free Press, 1951, Chapter 2 .

Etzioni, Amitai and Eva Etzioni-Haley, eds., Social Change: Sources, Patterns and Consequences, Basic Books, New York, 1973.

Fischer, C.S., "On Urban Alienations and Anomie," American Sociological Review 38, 1973.

Fischer, C.S., "Urbanism as a Way of Life: A Review and an Agenda," Sociological Methods and Research, I

(November 1972): 187-242. 
Gans, H.J., The Urban Villagers, New York: Free Press, 1962.

Gerbner, George, "Life According to T.V.," Newsweek,

(December 6, 1982): 136-40.

Greer, S., The Emerging City, New York: Free Press, 1962.

Guterman, S.S., "In Defense of Wirth's 'Urbanism as a Way of Life," American Journal of Sociology, 74 (March $1969)$ : $492-9$.

Inkeles, Alex, "Industrial Man," American Journal of Sociology, $66,1960$.

Israel, J., Alienation from Marx to Modern Sociology, Boston: Allyn and Bacon, 1971.

Keller, S., The Urban Neighborhood, New York: Random House, 1968 .

Kerlinger, Fred N., Behavioral Research, Holt-Rinehart and Winston, New York, 1979.

Key, William H., "Urbanism and Neighboring,' Sociological Quarterly, 6, 1965.

Killian, Lewis and Charles Grigg, "Urbanism, Race and Anomia," American Journal of Sociology, 67 (May 1962): $661-5$.

Knapp, Robert B., Social Integration in Urban Communities, New York: Columbia University Press, 1960.

McLuhan, Marshall, Quentin Fiore and Jeroma Agel, The Medium is the Message, New York: Random House, 1967.

McLuhan, Marshall, Understanding Media, New York: McGrawHill, 1964 .

Merton, Robert K., "Social Structure and Anomie," Social Theory and Social Structure, New York: Free Press, 1957.

Mizruchi, E.H., "Romanticism, Urbanism and Small Town in Mass Society: An Exploratory Analysis," in P. Meadows and E.H. Mizruchi, eds., Urbanism, Urbanization and Change: Comparative Perspectives, Reading, Mass: Addison-Wesley, 1969, 243-51.

National Opinion Research Center, Cumulative Code-Book, General Social Surveys 1972-80, Storrs CT, Roper Center, 1980 
Reiss, A.J., Jr., "Rural-Urban and Status Differences in Interpersonal Contacts," American Journal of Sociology, 65 (September 1959): 182-95.

Riesman, D., The Lonely Crowd, Garden City: Doubleday Anchor, 1953.

Rothman, Robert, Inequality and Stratification in the United States, Prentice-Hall, Englewood Cliffs, 1978.

Schact, R., Alienation, Garden City: Doubleday Anchor, 1953.

Seeman, M., "On the Meaning of Alienation," American Sociological Review, 24 (December 1959): 783-91.

Seeman, M., "The Urban Alienations: Some Dubious Theses from Marx to Marcuse," Journal of Personality and Social Psychology, 19 (August 1971): 135-43.

Seligson, Mitchell A., "Prestige Among Peasants,' American Journal of Sociology, 83, 1977.

Sjoberg, G., "The Rural-Urban Dimension in Preindustrial, Transitional, and Industrial Societies," in R.E. Faris (ed.), The Handbook of Modern Sociology, Chicago: Rand-McNally, 1964, 127-59.

Srole, Leo, "Social Integration and Certain Corollaries: An Exploratory Study," American Sociological Review, 25 (October 1960): 645-54.

Stein, M.R., The Eclipse of Community, New York: Harper Torchbook, 1964.

Tisdale, Hope, "The Process of Urbanization," Social Forces, $20(1942) ; 311-16$.

Toffler, Alvin, Future Shock, New York, Bantam Books, 1970.

Vidich, Arthur, and Joseph Bensman, Small Town in Mass Society, Princeton: Princeton University Press, 1958.

Whyte, W.F., Street Corner Society, Chicago: University of Chicago Press, 1955.

Wirth, I., "Urbanism as a Way of Life," American Journal of Sociology, 44 (July 1938): 3-24.

Wright, Erik Olin and Luca Perone, "Marxist Class Categories and Income Inequality," American Sociological Review, 42 (February 1977): 35-55. 
Wylie, L., Village in the Vaucluse, New York: Harper and Row, 1964 .

Young, M., and P. Willmott, Family and Kinship in East London, Baltimore: Penguin, 1957.

Young, Nancy F., "Changes in Values and Strategies Among Chinese in Hawaii," Sociology and Social Research, 56, 1972 . 


\section{APPENDIX A}

\section{Questions selected to operationalize variables}

Theoretical Questions.

1. Exposure to the Symbolism of Urban Life - "On the average day, about how many hours do you personally watch television?" (N.O.R.C. Cumulative Code Book, 1972-80, p. 161).

2. Social Class - "Respondent's Employment Status." (N.O.R.C. Cumulative Code Book, 1972-80, p. 18).

3. Everyday Activities - "Last week was your (wife/ husband) working full time, part time, going to school, keeping house or what?" (N.O.R.C. Cumulative Code Book, 1972-80, p. 20).

4. Physical Environment - "NORC Size of Place, 'Within an SMSA' 'Not within an SMSA.'" (N.O.R.C. Cumulative Code Book, 1972-80, p. 56).

\section{Attitudes.}

5. Happiness - "Taken all together, how would you say things are these days--would you say that you are very happy, pretty happy, or not too happy?" (N.O.R.C. Cumulative Code Book, 1972-80, p. 102).

6. Anomia1 - "It's hardly fair to bring a child into the world with the way things look for the future." (N.O.R.C. Cumulative Code Book, 1972-80, p. 133). 7. Anomia2 - "In spite of what some people say, the lot 
(situation/condition) of the average man is getting worse, not better." (N.O.R.C. Cumulative Code Book, $1972-80$, p. 133).

8. Life Satisfaction - "In general, do you find life exciting, pretty routine, or dull?" (N.O.R.C. Cumulative Code Book, 1972-80, p. 103).

9. Trust - "Generally speaking, would you say that most people can be trusted or that you can't be too careful in dealing with people?" (N.O.R.C. Cumulative Code Book, 1972-80, p. 103).

10. Aged in Home - "As you know, many older people share a home with their grown children. Do you think this is generally a good idea or a bad idea?" (N.O.R.C. Cumulative Code Book, 1972-80, p. 125).

Behaviors.

11. Membership in Professional Organization - "Now we would like to know something about the groups and organizations to which individuals belong. Here is a list of various kinds of organizations." Professional or academic societies? (N.O.R.C. Cumulative Code Book, $1972-80$, p. 128).

12. Membership in Political Organizations - "Political Clubs?" (N.O.R.C. Cumulative Code Book, 1972-80, p. 126).

13. Voting - "In 1976, you remember that Carter ran for President on the Democratic ticket against Ford for 
the Republicans. Do you remember for sure whether or not you voted in that election?" (N.O.R.C. Cumulative Code Book, 1972-80, p. 69).

14. Number of Children - "How many childen have you ever had? Please count all that were born alive at any time (including any you had from a previous marriage.)" (N.O.R.C. Cumulative Code Book, 1972-80, p. 27). 
APPENDIX B

TABLE 3.1

SUMMARY TABLE (MAIN EFFECTS)

ANOMIA1

\begin{tabular}{lrrrr} 
Source & \multicolumn{1}{c}{ SS } & d.f. & \multicolumn{1}{c}{ MS } & \multicolumn{1}{c}{ F } \\
\hline Population & 1.123 & 1 & 1.123 & 4.565 \\
Spouse works & .236 & 1 & .236 & .959 \\
TV Hours & 3.276 & 1 & 3.276 & $13.313^{*}$ \\
Social Class & .018 & 1 & .018 & .074 \\
$\quad$ ERROR & 141.505 & 575 & .246 & \\
Total & 147.679 & 590 & .250 & \\
E $^{2}=.04$ & & & &
\end{tabular}

TABLE 3.2

SUMMARY TABLE (MAIN EFFECTS)

LIFE SATISFACTION

Source

SS

d.f.

MS

F

Population

.570

.570

2.367

Spouse works

.007

.007

.030

TV Hours

5.684

1

5.684

$23.622 *$

Social Class

.538

1

.538

2.234

ERROR

138.362

575

.241

Total

147.343

590

.250

$E^{2}=.06$

*Statistically significant at .05 
TABLE 3.3

SUMMARY TABLE (MAIN EFFECTS)

MEMBERSHIP IN PROFESSIONAL ORGANIZATIONS

\begin{tabular}{lrrrr} 
Source & SS & d.f. & \multicolumn{1}{c}{ MS } & F \\
\hline Population & .479 & 1 & .479 & 4.365 \\
Spouse works & .425 & 1 & .425 & 3.875 \\
TV Hours & 1.468 & 1 & 1.468 & $13.396 *$ \\
Social Class & .103 & 1 & .103 & .942 \\
$\quad$ ERROR & 63.029 & 575 & .110 & \\
Total & 66.227 & 590 & .112 & \\
$E^{2}=.05$ & & & &
\end{tabular}

*Statistically significant at .05 
TABLE 3.4

SUMMARY TABLE (2 WAY INTERACTION)

NUMBER OF CHILDREN

Source

SS

d.f.

MS

F

Population $\mathrm{X}$

Spouse works

.069

1

.069

.308

Population $\mathrm{X}$

TV hours

.000

1

.000

.002

Population $\mathrm{X}$

Spouse works

.178

1

.178

.790

Spouse works X

TV Hours

.088

1

.088

.389

Spouse works X

Social Class

$$
.427
$$

1

.427

1.897

TV Hours X

Social Class

1.532

1

1.532

$6.796 \%$

ERROR
Total
$E^{2}=.03$

144.463

15

.335

149.482

641

.225

*Statistically significant at .05 
TABLE 3.5

SUMMARY TABLE ( 3 WAY INTERACTION)

MEMBERSHIP IN POLITICAL ORGANIZATION

\begin{tabular}{|c|c|c|c|c|}
\hline Source & SS & d.f. & MS & $F$ \\
\hline \multicolumn{5}{|l|}{ Population X } \\
\hline \multicolumn{5}{|l|}{ Spouse works X } \\
\hline TV Hours & .003 & 1 & .003 & .126 \\
\hline \multicolumn{5}{|l|}{ Population X } \\
\hline \multicolumn{5}{|l|}{ Spouse works X } \\
\hline Social Class & .004 & 1 & .004 & .175 \\
\hline \multicolumn{5}{|l|}{ Population X } \\
\hline \multicolumn{5}{|l|}{ TV Hours X } \\
\hline Social Class & .150 & 1 & .150 & $6.056 *$ \\
\hline \multicolumn{5}{|l|}{ Spouse works X } \\
\hline \multicolumn{5}{|l|}{ TV Hours $\mathrm{X}$} \\
\hline Social Class & .000 & 1 & .000 & .003 \\
\hline ERROR & 15.880 & 641 & .025 & \\
\hline Total & 16.560 & 656 & .025 & \\
\hline$E^{2}=.04$ & & & & \\
\hline
\end{tabular}

*Statistically significant at .05 
TABLE 3.6

SUMMARY TABLE ( 3 WAY INTERACTION)

TRUST

\begin{tabular}{|c|c|c|c|c|}
\hline Source & SS & d.f. & MS & $\mathrm{F}$ \\
\hline \multicolumn{5}{|l|}{ Population X } \\
\hline \multicolumn{5}{|l|}{ Spouse Works X } \\
\hline TV Hours & 1.493 & 1 & 1.493 & $6.012 *$ \\
\hline \multicolumn{5}{|l|}{ Population X } \\
\hline \multicolumn{5}{|l|}{ Spouse Works X } \\
\hline Social Class & .239 & 1 & .239 & .964 \\
\hline \multicolumn{5}{|l|}{ Population X } \\
\hline \multicolumn{5}{|l|}{ TV Hours X } \\
\hline Social Class & .004 & 1 & .004 & .017 \\
\hline \multicolumn{5}{|l|}{ Spouse Works X } \\
\hline \multicolumn{5}{|l|}{ TV Hours X } \\
\hline Social Class & .063 & 1 & .063 & .255 \\
\hline ERROR & 142.781 & 575 & .248 & \\
\hline Total & 147.729 & 590 & .250 & \\
\hline$E^{2}=.03$ & & & & \\
\hline
\end{tabular}

*Statistically significant at .05 
TABLE 3.7

SUMMARY TABLE ( 4 WAY INTERACTION)

HAPP INESS

\begin{tabular}{crrrr} 
Source & SS & d.f. & MS & $F$ \\
\hline Population X & & & & \\
Spouse works X & & & & \\
TV Hours X & & & & \\
Social Class & 1.235 & 1 & 1.235 & $5.072^{*}$ \\
ERROR & 156.060 & 641 & .243 & \\
Total & 161.501 & 656 & .246 & \\
$E^{2}=.03$ & & & &
\end{tabular}

TABLE 3.8

SUMMARY TABLE (MAIN EFFECTS)

VOTING BEHAVIOR

\begin{tabular}{lrrrr} 
Source & SS & d.f. & MS & F \\
\hline Population & .151 & 1 & .151 & .742 \\
Spouse works & .172 & 1 & .172 & .849 \\
TV Hours & .914 & 1 & .914 & 4.501 \\
Social Class & 1.501 & 1 & 1.501 & $7.393^{*}$ \\
$\quad$ ERROR & 130.143 & 641 & .203 & \\
Total & 133.775 & 656 & .204 & \\
$E^{2}=.03$ & & & &
\end{tabular}

*Statistically significant at .05 
TABLE 3.9

SUMMARY TABLE (MAIN EFFECTS)

ANOMIA2

\begin{tabular}{lrrrr} 
Source & \multicolumn{1}{c}{ SS } & d.f. & \multicolumn{1}{c}{ MS } & \multicolumn{1}{c}{ F } \\
\hline Popultion & .060 & 1 & .060 & .276 \\
Spouse works & 2.751 & 1 & 2.751 & $12.637 *$ \\
TV Hours & .715 & 1 & .715 & 3.283 \\
Social Class & 1.467 & 1 & 1.467 & 6.736 \\
$\quad$ ERROR & 139.558 & 641 & .218 & \\
Total & 146.000 & 656 & .223 & \\
E $^{2}=.04$ & & & &
\end{tabular}

TABLE 3.10

SUMMARY TABLE (MAIN EFFECTS)

AGED

\begin{tabular}{lrrrr} 
Source & SS & d.f. & MS & F \\
\hline Population & .058 & 1 & .058 & .232 \\
Spouse works & .735 & 1 & .735 & $2.956 *$ \\
TV Hours & .091 & 1 & .091 & .364 \\
Social Class & .000 & 1 & .000 & .001 \\
$\quad$ ERROR & 142.895 & 575 & .249 & \\
Total & 146.071 & 590 & .248 & \\
$E^{2}=.02$ & & & &
\end{tabular}

*Statistically significant at .05 